\title{
Micronutrient intakes and adequacy of intake in older adults in Ireland
}

\author{
Á. Hennessy ${ }^{1}$, J. Walton ${ }^{1}$, B. McNulty ${ }^{2}$, A. Nugent ${ }^{2}$, M. Gibney ${ }^{2}$ and A. Flynn ${ }^{1}$ \\ ${ }^{1}$ Irish Universities Nutrition Alliance (IUNA) at: School of Food and Nutritional Sciences, University College Cork, \\ Republic of Ireland and ${ }^{2}$ UCD Institute of Food and Health, University College Dublin, Belfield, \\ Dublin 4, Republic of Ireland
}

A growing body of evidence exists to support the role of micronutrients in healthy ageing. The objective of this study was to estimate micronutrient intakes and adequacy of intake in a sample of older adults ( $\geq 65$ years) in Ireland. Analysis was based on the National Adult Nutrition Survey (NANS), (2008-2010), which collected comprehensive dietary intake data of a representative sample of Irish adults $(n$ 1500) using a 4-day semi-weighed food and beverage record. A sub-sample of adults aged 65 years and over $(n 226)$ were selected and nutrient analyses were carried out using a modified version of WISP ${ }^{\mathcal{O}}$ (Tinuviel Software, Anglesey, UK), which encompasses both $\mathrm{UK}^{(1)}$ and Irish ${ }^{(2)}$ food composition data. Modifications included compositional updates for fortified foods, nutritional supplements and composite dishes. Adequacy of micronutrient intake was assessed using UK estimated average requirements $(\mathrm{EAR})^{(3)}$ and the Institute of Medicine's $\mathrm{EAR}^{(4)}$ in the case of vitamin D. Under-reporters (URs), defined using minimum energy intake cut-off points 5 , calculated as multiples of BMR (Tanita BC 420MA Body Composition Analyser), were excluded from the analysis.

Daily micronutrient intakes of older adults (mean and SD), (excluding URs) and the proportion with intakes below the EAR are reported in the table below.

\begin{tabular}{|c|c|c|c|c|c|c|}
\hline & \multicolumn{3}{|c|}{ Men $(n=75)$} & \multicolumn{3}{|c|}{ Women $(n=87)$} \\
\hline & Mean & SD & $\%<\mathrm{EAR}$ & Mean & $\mathrm{SD}$ & $\%<$ EAR \\
\hline Vitamin A $(\mu \mathrm{g})$ & 1492 & 812 & $8 \cdot 0$ & 1425 & 813 & $3 \cdot 4$ \\
\hline Vitamin $\mathrm{D}(\mu \mathrm{g})$ & $5 \cdot 6$ & $4 \cdot 0$ & $85 \cdot 3$ & $8 \cdot 7$ & $9 \cdot 6$ & $74 \cdot 7$ \\
\hline Thiamin (mg) & $2 \cdot 0$ & $0 \cdot 8$ & $0 \cdot 0$ & $3 \cdot 2$ & $6 \cdot 6$ & $0 \cdot 0$ \\
\hline Riboflavin (mg) & $2 \cdot 1$ & $0 \cdot 8$ & $9 \cdot 3$ & $3 \cdot 6$ & $8 \cdot 2$ & $5 \cdot 7$ \\
\hline Total niacin (mg) & $42 \cdot 5$ & $14 \cdot 4$ & $0 \cdot 0$ & $44 \cdot 0$ & $45 \cdot 2$ & $0 \cdot 0$ \\
\hline Vitamin B6 (mg) & $3 \cdot 3$ & $1 \cdot 6$ & $0 \cdot 0$ & $4 \cdot 6$ & $9 \cdot 3$ & $0 \cdot 0$ \\
\hline Vitamin B12 $(\mu \mathrm{g})$ & $7 \cdot 1$ & $5 \cdot 0$ & $0 \cdot 0$ & $7 \cdot 2$ & $7 \cdot 7$ & $2 \cdot 3$ \\
\hline Folate $(\mu \mathrm{g})$ & 497 & 615 & $8 \cdot 0$ & 382 & 236 & $10 \cdot 3$ \\
\hline Vitamin C (mg) & 105 & 154 & $14 \cdot 7$ & 127 & 188 & $5 \cdot 7$ \\
\hline Calcium (mg) & 986 & 399 & $8 \cdot 0$ & 1106 & 615 & $8 \cdot 0$ \\
\hline Magnesium (mg) & 305 & 108 & $37 \cdot 3$ & 283 & 137 & $28 \cdot 7$ \\
\hline Iron (mg) & $17 \cdot 4$ & $20 \cdot 4$ & $6 \cdot 7$ & $14 \cdot 7$ & $26 \cdot 0$ & $10 \cdot 3$ \\
\hline Zinc (mg) & $10 \cdot 9$ & $4 \cdot 5$ & $18 \cdot 7$ & $11 \cdot 1$ & $12 \cdot 5$ & $12 \cdot 6$ \\
\hline
\end{tabular}

Our study found that a significant proportion of older adults had inadequate intakes for vitamin $\mathrm{D}$ and magnesium. Inadequate intakes $(>10 \%)$ were observed for vitamin $\mathrm{C}$ and zinc in men, and for zinc, iron and folate in older women. These findings highlight the need to investigate strategies to address low micronutrient intake in older adults.

This research was funded by the Department of Agriculture, Food and the Marine under the Food Institutional Research Measure (FIRM).

1. Food Standards Agency (2002) Cambridge: Royal Society of Chemistry.

2. Black LJ, Ireland J, Møller A, et al. (2011) J Food Comp Anal 24, 1017-1023.

3. Department of Health (1991) London: H.M.S.O.

4. Food and Nutrition Board (2011) Washington D.C.: Institute of Medicine. 